Article

\title{
Body Composition in Women after Radical Mastectomy
}

\section{Jacek Wilczyński *®D, Piotr Sobolewski ${ }^{\circledR}$, Rafał Zieliński and Magdalena Kabała}

Laboratory of Posturology, Collegium Medicum, Jan Kochanowski University, 25-369 Kielce, Poland; piotrsobolewski@poczta.onet.pl (P.S.); rafal.zielinski@ujk.edu.pl (R.Z.); magdalena.kabala@onet.eu (M.K.)

* Correspondence: jwilczynski@onet.pl; Tel.: +48-603-703-926

Received: 15 October 2020; Accepted: 27 November 2020; Published: 2 December 2020

\begin{abstract}
The aim of the study was to analyse the body composition among women after radical mastectomy. The body compositions of 30 women after radical mastectomy (study group) were compared with those of 30 healthy females (control group). The method of electrical bioimpedance was used to analyse body composition. The significant differences between the groups, unfavourable for women, following mastectomy concerned body mass $(p=0.021)$, BMI $(p=0.049)$, fat mass $(\%)$ $(p=0.007)$, fat mass $(\mathrm{kg})(p=0.005)$, total body water $(\%)(p=0.002)$, left upper limb fat mass $(p=0.013)$ as well as right upper limb fat mass $(p=0.022)$. The body composition of women after radical mastectomy was significantly worse compared to the control group. The majority of subjects were overweight and had high levels of body fat. Abnormal body composition is a modifiable risk factor of breast cancer; therefore, improving lifestyle is important in the prevention and treatment of this disease. There is a need for education, dietary supervision and physical activity in women following radical mastectomy. The innovation of our study was the use of the modern bioelectrical impedance analysis (BIA) method, which does not cause ionisation and is a gold standard in the field of body composition analysis. In future research, we plan to broaden the assessment of lifestyle and the significance of diet and physical activity in the prevention and treatment of breast cancer.
\end{abstract}

Keywords: radical mastectomy; body composition; electrical bioimpedance

\section{Introduction}

Breast cancer is the most common malignant neoplasm diagnosed in women. Approximately 1 million new cases are diagnosed in the world each year. About 500,000 new and existing patients will die from breast cancer [1,2]. Postmenopausal women with abnormal body composition and obesity are at a higher risk of developing this disease [3,4]. In obese women, additional diagnostic difficulties occur, as well as an increased risk of complications during treatment and a greater likelihood of recurrence of the disease. There is also a greater risk of developing cancer of the other breast $[5,6]$. The risk of breast cancer in obese postmenopausal women is three times higher than that in lean women with normal body composition [7,8]. Adipose tissue is an endocrine structure that secretes biologically active substances. The association between body composition disorders and breast cancer is due to the metabolic interaction between oestrogens from peripheral aromatisation, the role of the insulin/insulin-like growth factor axis and the function of adipocytes as an endocrine organ. In many studies, a correlation has been demonstrated between excess body mass and breast cancer. Overweightness and obesity are characterized as excessive accumulation of fatty tissue in the body [9].

Obesity, defined by WHO as a chronic disease, is a long-term inflammatory process [10]. As a result, excessive secretion of pro-inflammatory substances (TNF- $\alpha$, IL-6, visfatin, resistin) occurs, while the concentration of anti-inflammatory substances (adiponectin, IL-1, IL-10) is reduced [11]. This leads to increased cell proliferation, inhibition of apoptosis, stimulation of angiogenesis and 
damage to genetic material. All of this increases the risk of developing breast cancer. People with excess body mass often eat inconsistently with the generally accepted health recommendations [12]. A high-fat, low-fibre diet with a high glycaemic index and a low consumption of vegetables and fruits promotes the development of both obesity and breast cancer. The problem of excessive adipose tissue concerns not only anti-cancer prevention, but it also affects the course of treatment and prognosis [13]. Consequently, there is a need for nutritional education among cancer patients and dietary supervision in the case of weight reduction for obese cancer patients [14,15].

The limited efficiency of clinical trials and a reluctance to participate in screening tests result in a higher stage of the disease at diagnosis, which translates into worse treatment outcomes [16]. Obese people are at a greater risk of any type of anaesthesia, an increased risk of technical difficulties during breast cancer surgery, in wound infection and in the rate of wound revision due to bleeding, as well as an increased risk in the number of thromboembolic complications and the risk of limb oedema following lymphatic surgery. The course of the disease is significantly worse in obese women, which is confirmed by the results of clinical trials [11]. Abnormal body composition is a modifiable risk factor for breast cancer. Improving lifestyle to reduce overweightness and obesity may have significant impact on reducing the incidence of and deaths from breast cancer $[17,18]$.

Currently, the significance of regular physical activity in the prevention of breast cancer is more and more emphasized. The aim of systematic physical activity is to support the rehabilitation process [19]. It is about, among others, restoring normal muscular-ligamentous-joint functions. Properly selecting the intensity of exercise is an important element of primary and secondary prevention of breast cancer [20]. In many publications, the significant, positive effect of physical activity in reducing the incidence of breast cancer is described. It is indicated that the occurrence of breast cancer is greatly lower in physically active women [21]. Physical activity also prevents post-mastectomy complications [22]. Moreover, it positively influences the limitation and reduction of lymphoedema, prevents overweightness and improves physical fitness as well as body statics [23].

The aim of the study was to analyse the body composition of women following radical mastectomy.

\section{Materials and Methods}

The study comprised 60 women aged 45 to 60 . The study group (1) consisted of 30 women following radical mastectomy (right, left), whereas in the control group (2), there were 30 healthy women with similar anthropometric parameters and of similar age. All examined patients were right-handed. The inclusion criterion for the study was 3 to 4 years following the surgery. In the study group, $13(43.33 \%)$ women underwent left radical mastectomy, while 17 (56.67\%) women underwent right radical mastectomy. The adjuvant treatment included radiotherapy in $23(76.67 \%)$ women, followed by hormone therapy in $22(73.33 \%)$ women and chemotherapy in $19(63.33 \%)$ women. The patients did not have lymphedema.

Basic somatic features were examined. Body height was measured with an anthropometer to the nearest $5 \mathrm{~mm}$, while body mass was estimated with an electronic scale to the nearest $0.5 \mathrm{~kg}$. Based on the obtained data, body mass index was calculated. The method of electrical bioimpedance (BIA) was used to analyse body composition. BIA (bioelectrical impedance analysis) was used to measure impedance, which is the electrical resistance comprising the resistance and reactance of the tissues through which a low electric current $(\leq 1 \mathrm{~mA})$ is passed. The phenomenon of resistance is related to the specific resistance of individual tissues, while reactance is mainly caused by the electric capacity of cell membranes, which, due to their structure, act as capacitors. Adipose tissue has a low water content and, therefore, is more resistant to an electrical signal, while muscle tissue has a high water content and, thus, conducts electricity with less resistance. However, factors such as ambient temperature, previous exercise, fluid intake, health state, menstrual cycle, medications, alcohol, caffeine, etc., may also affect tissue hydration levels and test results. The time of day can also influence water content as well as fluid distribution in the body. This is why measurements are most consistent when taken before the evening meal. In order to obtain the most accurate measurements, they were always carried out at the 
same time by the same trained person (between 18:00 and 20:00 p.m.) and under the same conditions, e.g., always before a meal. The BIA method used in TANITA analysers is a gold standard in the field of body composition analysis. The accuracy of the measurement is as follows: body mass $50 \mathrm{~g}$; fatty tissue content $0.1 \%$; muscle tissue content $50 \mathrm{~g}$; body water content $0.1 \%$. We also bore in mind a few contraindications, e.g., pregnancy and pacemakers [24].

The test was performed using the TANITA MC-780 device. As a result of the measurement, the following variables were obtained: body mass $(\mathrm{kg})$, metabolic age, body mass index (BMI), fat mass FM (\%), fat mass-FM (kg), fat-free mass-FFM ( $\mathrm{kg})$, muscle mass-MM (kg), total body water-TBW $(\mathrm{kg})$ and total body water-TBW (\%), muscle mass of the left upper limb-MMLUL (kg), muscle mass of the right upper limb-MMRUL (kg), left upper limb fat mass-LULFM (kg) and right upper limb fat mass-RULFM (kg). The study was performed in 2019 at the Posturology Laboratory. All research procedures were performed in accordance with the 1964 Declaration of Helsinki and with the consent of the University Bioethics Committee No. 31/2018. Measurement data were collected on an MS Excel spreadsheet. After pre-treatment, they were imported to the Statistica 13 program. The analysis included anthropometric and body composition variables, both in the study (1) and control group (2). The selection of statistical analysis methods was determined by the type of analysed variables (quantitative variables). For the analysed quantitative variables, both describing the age of the subjects, body mass and height, metabolic age and body composition, arithmetic means (x), standard deviations (s), medians (Me) and extreme values were calculated. Normality of distribution for the variables was checked using the Kolmogorov-Smirnov test. The non-parametric Mann-Whitney $U$ test was used to demonstrate the differences between the study group (1) and the control group (2). This test allows a comparison between each of the observations against the median, not the mean. Therefore, when reporting its results, attention was paid to the median value in both groups, and conclusions were drawn on this basis. The level of statistical significance was $p<0.05$.

\section{Results}

In the study group (1), there were 17 (56.67\%) women post right-sided mastectomy and $13(43.33 \%)$ women post left-sided mastectomy. The mean age in the study group (1) was 55.07 years, and in the control group (2) 50.27 years. There were no significant differences in body height between the study (1) and control (2) group $(p=0.622)$. The mean body mass for the study group (1) was $73.01 \mathrm{~kg}$, and for the control group (2) it was $65.95 \mathrm{~kg}$. Body mass differed significantly between the groups $(p=0.021)$.

BMI in the test group (1) was $27.56 \mathrm{~kg} / \mathrm{m}^{2}$, and in the control group (2) it was $24.96 \mathrm{~kg} / \mathrm{m}^{2}$. There were significant differences in BMI between the study group (1) and the control group (2) $(p=0.049)$, as well as significant differences in metabolic age between the studied groups $(p=0.001)$. BMI in the test group (1) was $27.56 \mathrm{~kg} / \mathrm{m}^{2}$, and in the control group (2), $24.96 \mathrm{~kg} / \mathrm{m}^{2}$. There were significant differences in BMI between the study (1) and control (2) group ( $p=0.049)$ (Table 1).

The mean fat mass (\%) in the study group (1) was 34.03\%, and in the control group (2), $29.16 \%$. There was a significant difference in fat mass (\%) between the two groups $(p=0.007)$. The mean fat mass (kg) in the study group (1) was $24.99 \mathrm{~kg}$, and in the control group (2) it was $19.33 \mathrm{~kg}$. There was a significant difference in fat mass $(\mathrm{kg})$ between groups $(p=0.005)$. The mean lean mass $(\mathrm{kg})$ for the study group (1) was $48.59 \mathrm{~kg}$, and for the control group (2), $46.96 \mathrm{~kg}$. There were no significant differences in lean mass $(\mathrm{kg})$ between groups $(p=0.224)$.

The mean muscle mass ( $\mathrm{kg}$ ) for the study group (1) was $47 \mathrm{~kg}$, and for the control group (2), this totalled $43.97 \mathrm{~kg}$. There were no significant differences in muscle mass $(\mathrm{kg})$ between groups $(p=0.109)$. The mean total water content $(\mathrm{kg})$ in the study group (1) was $34.42 \mathrm{~kg}$, and in the control group (2) it was, $33.37 \mathrm{~kg}$. There were no significant differences in total water content $(\mathrm{kg})$ between the groups $(p=0.236)$.

The mean total water content (\%) in the study group (1) was $47.59 \%$, while in the control group (2), this equalled $51.16 \%$. There was a significant difference in total water content (\%) between groups $(p=0.002)$. Metabolic age in the study group (1) was 51.00 years, and in the control group it was 
39.83 years (2). There were significant differences in metabolic age between the examined groups $(p=0.001)$ (Table 1).

Left upper limb muscle mass ( $\mathrm{kg}$ ) in the study group (1) was $2.27 \mathrm{~kg}$, and in the control group (2) this amounted to $2.18 \mathrm{~kg}$. There were no significant differences in left upper limb muscle mass $(\mathrm{kg})$ between the groups $(p=0.254)$. The muscle mass of the right upper limb $(\mathrm{kg})$ in the study group (1) was $2.29 \mathrm{~kg}$, and in the control group (2), $2.18 \mathrm{~kg}$. There were no significant differences in right upper limb muscle mass $(\mathrm{kg})$ between the groups $(p=0.213)$. The mass of the left upper limb fat $(\mathrm{kg})$ in the test group (1) was $1.54 \mathrm{~kg}$, and in the control group it was $1.09 \mathrm{~kg}$ (2). There was a significant difference in left upper limb fat mass $(\mathrm{kg})$ between groups $(p=0.013)$. The mass of the right upper limb fat $(\mathrm{kg})$ in the study group (1) was $1.42 \mathrm{~kg}$, while in the control group (2) it was 1.03. There was a significant difference in the mass of right upper limb fat $(\mathrm{kg})$ between the examined groups $(p=0.022)$ (Table 1$)$.

Table 1. Somatic features and body composition in the study (1) and control (2) groups.

\begin{tabular}{|c|c|c|c|c|c|c|c|}
\hline \multirow{2}{*}{ Variables } & \multicolumn{6}{|c|}{ Descriptive Statistics of the Analysed Scales } & \multirow{2}{*}{$\begin{array}{c}\text { Mann-Whitney } \\
\text { U Test }\end{array}$} \\
\hline & Group & $X$ & SD & Min & Med & Max & \\
\hline \multirow{2}{*}{ Age (years) } & 1 & 55.07 & 4.71 & 45.00 & 55.50 & 60.00 & \multirow{2}{*}{$p=0.001$} \\
\hline & 2 & 50.27 & 5.13 & 45.00 & 49.00 & 60.00 & \\
\hline \multirow{2}{*}{ Height (cm) } & 1 & 163.03 & 4.49 & 152.00 & 164.00 & 173.00 & \multirow{2}{*}{$p=0.622$} \\
\hline & 2 & 162.40 & 4.76 & 152.00 & 164.00 & 176.00 & \\
\hline \multirow{2}{*}{ Body mass (kg) } & 1 & 73.01 & 12.93 & 46.50 & 69.75 & 104.50 & \multirow{2}{*}{$p=0.021$} \\
\hline & 2 & 65.95 & 11.21 & 49.90 & 62.30 & 92.90 & \\
\hline \multirow{2}{*}{ Metabolic age } & 1 & 51.00 & 13.04 & 29.00 & 50.00 & 83.00 & \multirow{2}{*}{$p=0.001$} \\
\hline & 2 & 39.83 & 10.73 & 27.00 & 34.00 & 63.00 & \\
\hline \multirow{2}{*}{ BMI $\left(\mathrm{kg} / \mathrm{m}^{2}\right)$} & 1 & 27.56 & 5.32 & 18.20 & 26.65 & 40.10 & \multirow{2}{*}{$p=0.049$} \\
\hline & 2 & 24.96 & 3.73 & 18.60 & 24.40 & 32.80 & \\
\hline \multirow{2}{*}{ Fat mass (\%) } & 1 & 34.03 & 8.96 & 13.50 & 33.55 & 66.50 & \multirow{2}{*}{$p=0.007$} \\
\hline & 2 & 29.16 & 8.58 & 14.00 & 27.65 & 60.20 & \\
\hline \multirow{2}{*}{ Fat mass (kg) } & 1 & 24.99 & 8.39 & 6.30 & 23.65 & 44.00 & \multirow{2}{*}{$p=0.005$} \\
\hline & 2 & 19.33 & 7.11 & 7.00 & 18.05 & 36.50 & \\
\hline \multirow{2}{*}{ Fat-free mass (kg) } & 1 & 48.59 & 5.57 & 40.20 & 47.80 & 60.50 & \multirow{2}{*}{$p=0.224$} \\
\hline & 2 & 46.96 & 5.38 & 39.70 & 45.70 & 62.40 & \\
\hline \multirow{2}{*}{ Muscle mass (kg) } & 1 & 47.00 & 6.78 & 38.10 & 46.30 & 69.60 & \multirow{2}{*}{$p=0.109$} \\
\hline & 2 & 43.97 & 6.29 & 24.50 & 43.40 & 59.30 & \\
\hline \multirow{2}{*}{ Total body water (kg) } & 1 & 34.42 & 3.97 & 28.30 & 33.85 & 43.00 & \multirow{2}{*}{$p=0.236$} \\
\hline & 2 & 33.37 & 3.85 & 28.00 & 32.45 & 44.40 & \\
\hline \multirow{2}{*}{ Total body water (\%) } & 1 & 47.59 & 4.68 & 39.50 & 47.20 & 61.30 & \multirow{2}{*}{$p=0.002$} \\
\hline & 2 & 51.16 & 4.50 & 43.30 & 51.60 & 61.30 & \\
\hline \multirow{2}{*}{ Muscle mass of left upper limb } & 1 & 2.27 & 0.31 & 1.80 & 2.20 & 2.80 & \multirow{2}{*}{$p=0.254$} \\
\hline & 2 & 2.18 & 0.30 & 1.80 & 2.15 & 3.00 & \\
\hline \multirow{2}{*}{ Muscle mass of right upper limb } & 1 & 2.29 & 0.34 & 1.80 & 2.20 & 3.00 & \multirow{2}{*}{$p=0.213$} \\
\hline & 2 & 2.18 & 0.30 & 1.80 & 2.10 & 3.10 & \\
\hline & 1 & 1.54 & 0.77 & 0.20 & 1.30 & 3.50 & $n=0.013$ \\
\hline Fat mass of left upper limb & 2 & 1.09 & 0.52 & 0.30 & 1.00 & 2.20 & $p=0.013$ \\
\hline Fa & 1 & 1.42 & 0.69 & 0.20 & 1.20 & 3.30 & \\
\hline Fat mass or upper rignt $11 \mathrm{mb}$ & 2 & 1.03 & 0.48 & 0.20 & 0.90 & 2.00 & \\
\hline
\end{tabular}

\section{Discussion}

One of the significant risk factors for developing breast cancer, apart from genetic determinants, is inappropriate diet and the associated accumulation of adipose tissue [25]. Excess body fat is associated with an overgrowth of adipocytes. In women with a normal BMI, the overgrowth of breast adipocytes correlates with inflammation of white adipose tissue, increased levels of aromatase (an enzyme that limits the rate of oestrogen biosynthesis) and increased blood leptin levels [26,27]. Importantly, it is suggested that insulin resistance, inflammation of the adipose tissue of the breast, elevated aromatase expression and elevated leptin levels play roles in the pathogenesis of obesity-related breast cancer [28]. 
Obesity increases the risk of breast cancer, especially in postmenopausal women [29]. The menopausal period is associated with hormonal changes that directly affect a woman's body composition. First of all, the share of adipose tissue in the total body mass and that located in the abdominal area increases [30]. In the case of most women, following a mastectomy, the distribution of adipose tissue occurs in the android form where fat is mainly located in the upper body, especially in the abdomen and chest [31]. The results of our study, as well as previous reports, confirm that after a mastectomy a significant percentage of women are overweight or obese [32]. Among obese women, deficits in maintaining balance may result from various functional determinants of postural stability [33]. This may be due to a slower response because of increased inertia of body segments, increased joint stiffness or decreased mobility due to excess body fat [34].

In the research by McTiernan et al. [35], it has been shown that obesity and a sedentary lifestyle increase the risk of breast cancer by about $25-33 \%$. Additionally, the results of a meta-analysis by Chan et al. [36] demonstrated that obese women were at a 35\% higher risk of dying from breast cancer compared to those with normal body mass. Treatment of breast cancer is associated with an increase in body fat as well as a decrease in lean body mass and bone mineral density. These changes can increase the risk of brittle fractures and the formation of osteoporosis, and they may lead to the reoccurrence of cancer. Maintaining proper norms of body composition should be part of important preventive measures among women, especially those over 50 [36].

In our study, taking into account bioelectrical impedance analysis (BIA) in women after unilateral mastectomy, a greater amount of fat mass was observed when compared to the control group. Statistical significance was demonstrated in terms of fat mass $(\mathrm{kg})(p=0.005)$ and fat mass $(\%)$ $(p=0.007)$ between the study and control groups. Additionally, the content of fat mass in the left and right upper limbs among women after radical mastectomy was higher in the study than in the control group. Statistical significance was demonstrated between the groups $p=0.013$ and $p=0.022$, respectively. In our research, as well as in that by Coin et al. [37], it was confirmed that the right arm has slightly less fat tissue than the left arm.

In a study by Gomes et al. [38], 95 women were examined (including 49 women from the study group, six months after surgery for breast cancer and 46 women from the control group). In that study, women who underwent left-sided radical mastectomy showed a greater total lean mass compared to women who underwent right-sided radical mastectomy. In women with excessive lymphedema, an increase in the volume of adipose and lean tissue on the affected side was observed. Among patients after breast cancer treatment, there was often a combination of weight loss with a build-up of fat, i.e., so-called sarcopenic obesity. The full aetiology of the loss of lean body mass requires further research; however, it may be associated with worse metabolic outcomes associated with the development of cardiovascular diseases or metabolic syndrome [38].

Vance et al. [39], based on an analysis of the literature from 1975 to 2009, showed that weight gain is more common in women receiving adjuvant chemotherapy, especially among those undergoing longer treatment, and it seems to be particularly pronounced in premenopausal women. With or without weight gain, there are adverse changes in body composition, including increased fat and loss of lean tissue [39].

Additionally, van den Berg et al. [40] performed a meta-analysis in which they also indicated that there is significant weight gain during chemotherapy in women with breast cancer. Moreover, chemotherapy promotes disorders of muscle metabolism (deregulation of adenosine triphosphate, cytokines and depletion of satellite cells occurs) and also leads to the destruction of muscle, which may weaken muscle strength and reduce the level of fitness [40].

Although physical activity is a lifestyle element crucial in maintaining physical fitness and directly influences the perceived quality of life, reports on this subject differ [41]. In one study, no significant differences were found in the level of physical activity undertaken before or after mastectomy. This treatment did not affect the frequency, type or form of rest among the respondents. The participants presented a general, average level of knowledge about the influence of physical activity 
on the reduction in disease recurrence risk. Only half of the respondents were aware of the influence of exercise on general fitness and physical health as well as mental health [42]. In a different study, it has been shown that women change their eating habits when diagnosed with a disease but, at the same time, do not increase physical activity despite its beneficial effects on quality of life and prevention of cancer recurrence [43]. In yet another study, we found information indicating that mastectomy surgery and the lack of habitual movement in this group of people cause a decrease in physical activity, and thus, a lack of it being regularly performed [44]. According to the respondents, the main obstacles hindering physical activity are household chores, lack of time or poor health. Other authors also cite limitations such as fatigue, pain and reluctance to exercise. There are also barriers closely related to the effects of the disease and its treatment, including the following: secondary lymphoedema, fear of pain, lack of information about permitted types of activity, bad mood, depression and apathy. However, there are also studies in which it is shown that having had a past mastectomy significantly increased the frequency of undertaking physical exercise. This may indicate an increase in awareness of the need to perform physical activity [44].

Despite the proven influence of the increased content of adipose tissue in the body as a significant factor in the aetiology of breast cancer, the distribution of this tissue has not been fully elucidated and requires further research $[45,46]$. Assessing women's body composition can be an important indicator of metabolic disorders and disease progression.

\section{Conclusions}

The body composition of women after radical mastectomy was significantly worse compared to the control group. Most of the subjects were overweight and had high levels of body fat. Abnormal body composition is a modifiable risk factor for breast cancer; therefore, improving lifestyle is important in the prevention and treatment of this disease. There is a need for education, dietary supervision and physical activity among women after having a radical mastectomy. The innovation of our study was the use of the modern BIA method, which does not cause ionisation and is a gold standard in the field of body composition analysis. In future studies, we plan to broaden the assessment of lifestyle and the importance of diet and physical activity in the prevention and treatment of breast cancer.

Author Contributions: J.W.: conceptualisation, data collection and analysis, formal analysis, methodology, writing-review and editing. P.S.: writing-original draft. R.Z.: writing-review and editing. M.K.: data collection and analysis, formal analysis, writing-review and editing. All authors have read and agreed to the published version of the manuscript.

Funding: The project is supported within the framework of the programme funded by the Minister of Science and Higher Education under the name "Regional Initiative of Excellence" in 2019-2022, project number: 024/RID/2018/19.

Data Availability: The data used to support the findings of this study are available from the corresponding author upon request.

Conflicts of Interest: The authors declare no conflict of interest regarding the publication of this paper.

\section{References}

1. Miller, A.B. Early detection of breast cancer in the emerging world. Zent. Gynakol. 2006, 128, $191-195$. [CrossRef]

2. Smigal, C.; Jemal, A.; Ward, E.; Cokkinides, V.; Smith, R.; Howe, H.L.; Thun, M. Trends in breast cancer by race and ethnicity: Update 2006. CA Cancer J. Clin. 2006, 56, 168-183. [CrossRef]

3. Matsuno, R.K.; Anderson, W.F.; Yamamoto, S.; Tsukuma, H.; Pfeiffer, R.M.; Kobayashi, K.; Devesa, S.S.; Levine, P.H. Early- and late-onset breast cancer types among women in the United States and Japan. Cancer Epidemiol. Biomark. Prev. 2007, 16, 1437-1442. [CrossRef]

4. Garland, M.; Fang-Chi, H.; Clark, C.; Chiba, A.; Howard-McNatt, M. The impact of obesity on outcomes for patients undergoing mastectomy using the ACS-NSQIP data set. Breast Cancer Res. Treat. 2018, 168, 723-726. [CrossRef] 
5. Socha, M.; Bolanowski, M.; Jonak, W.; Górska-Kłęk, L.; Chwałczyńska, A.; Stanisławska, M. Total fatness and fatty tissue distribution in women after mastectomy. Endocrinol. Obes. Metab. Disord. 2008, 5, 7-12.

6. Czerniak, U.; Demuth, A.; Skrzypczak, M. Associations of physical activity and inactivity with body tissue composition among healthy Polish women and women after mastectomy. Homo J. Comp. Hum. Biol. 2014, 65, 423-431. [CrossRef]

7. Iyengar, N.M.; Morris, P.G.; Zhou, X.K.; Gucalp, A.; Giri, D.; Harbus, M.D.; Falcone, D.J.; Krasne, M.D.; Vahdat, L.T.; Subbaramaiah, K.; et al. Menopause is a determinant of breast adipose inflammation. Cancer Prev. Res. 2015, 8, 349-358. [CrossRef]

8. Milewska, M.; Mioduszewska, M.; Pańczyk, M.; Kucharska, A. Two compartment model of body composition and abdominal fat area in postmenopausal women-pilot study. Med. News 2016, 69, 169-173.

9. Leclerc, A.F.; Foidart-Dessalle, M.; Tomasella, M.; Coucke, P.; Devos, M.; Bruyère, O.; Bury, T.; Deflandre, D.; Jerusalem, G.; Lifrange, E.; et al. Multidisciplinary rehabilitation program after breast cancer: Benefits on physical function, anthropometry and quality of life. Eur. J. Phys. Rehabil. Med. 2017, 53, 633-642. [CrossRef] [PubMed]

10. Artene, D.V.; Bordea, C.I.; Blidaru, A. Results of 1-year Diet and Exercise Interventions for

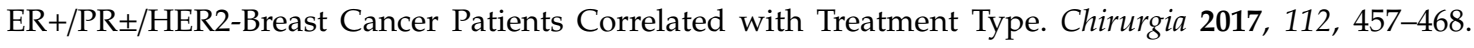
[CrossRef]

11. Fredslund, S.O.; Gravholt, C.H.; Laursen, B.E.; Jensen, A.B. Key metabolic parameters change significantly in early breast cancer survivors: An Explorative PILO Study. J. Transl. Med. 2019, 17, 105. [CrossRef]

12. Iyengar, N.M.; Brown, K.A.; Zhou, X.K.; Gucalp, A.; Subbaramaiah, K.; Giri, D.D.; Zahid, H.; Bhardwaj, P.; Wendel, N.K.; Falcone, D.J.; et al. Metabolic obesity, adipose inflammation and elevated breast aromatase in women with normal body mass index. Cancer Prev. Res. 2017, 10, 235-243. [CrossRef] [PubMed]

13. Carayol, M.; Ninot, G.; Senesse, P.; Bleuse, J.P.; Gourgou, S.; Sancho-Garnier, H.; Sari, H.; Romieu, I.; Romieu, G.; Jacot, W. Short- and long-term impact of adapted physical activity and diet counseling during adjuvant breast cancer therapy: The "APAD1" randomized controlled trial. BMC Cancer 2019, 19, 1-20. [CrossRef]

14. Van den Berg, M.M.G.A.; Kok, D.E.; Posthuma, L.; Kamps, L.; Kelfkens, C.S.; Buist, N.; Geenen, M.; Haringhuizen, A.; Heijns, J.B.; van Lieshout, R.H.M.A.; et al. Body composition is associated with risk of toxicity-induced modifications of treatment in women with stage I-IIIB breast cancer receiving chemotherapy. Breast Cancer Res. Treat. 2019, 173, 475-481. [CrossRef]

15. WHO. Waist Circumference and Wais-Hip Ratio, Report of a WHO Expert Consultation; WHO: Geneva, Switzerland, 2008; ISBN 978-92-4-150149-1.

16. Demuth, A.; Czerniak, U. Overweight and obesity among adult women. J. Kinesiol. Exerc. Sci. 2009, 47, 59-63.

17. Dutil, M.; Handrigan, G.A.; Corbeil, P.; Cantin, V.; Simoneau, M.; Teasdale, N.; Hue, O. The impact of obesity on balance control in community-dwelling older women. Age 2013, 35, 883-890. [CrossRef]

18. Ostrowska, B.; Mraz, M. Body mass index and postural stability in older women with osteoporosis. Gerontol. Wspótczesna 2014, 2, 141-145.

19. Kruk, J. Intensity of recreational physical activity in different life periods in relation to breast cancer among women in the region of Western Pomerania. Contemp. Oncol. 2012, 16, 576-581. [CrossRef]

20. Ligibel, J.A.; Partridge, A.; Giobbie-Hurder, A.; Golshan, M.; Emmons, K.; Winer, E.P. Physical activity behaviors in women with newly diagnosed ductal carcinoma-in-situ in a longitudinal cohort study. Ann. Surg. Oncol. 2009, 16, 106-112. [CrossRef]

21. Hsieh, C.; Sprod, L.K.; Hydock, D.S.; Carter, S.D.; Hayward, R.; Schneider, C.M. Effects of a Supervised Exercise Intervention on Recovery from Treatment Regimens in Breast Cancer Survivors. Oncol. Nurs. Forum. 2008, 35, 909-915. [CrossRef]

22. Pierce, J.; Stefanick, M.; Flatt, S. Greater survival after breast cancer in physically active women with high vegetable-fruit intake regardless of obesity. J. Clin. Oncol. 2007, 17, 2345-2351. [CrossRef]

23. Penttinen, H.M.; Saarto, T.; Kellokumpu-Lehtinen, P.; Blomqvist, C.; Huovinen, R.; Kautiainen, H.; Järvenpää, S.; Nikander, R.; Idman, I.; Luoto, R.; et al. Quality of life and physical performance and activity of breast cancer patients after adjuvant treatments. Psychooncology 2011, 20, 1211-1220. [CrossRef]

24. Kabała, M.M.; Wilczyński, J. Obesity and postural stability in women after mastectomy. Med. Stud. 2019, 35, $48-54$. 
25. Thomas, G.A.; Cartmel, B.; Harrigan, M.; Fiellin, M.; Capozza, S.; Zhou, Y.; Ercolano, E.; Gross, C.P.; Hershman, D.; Ligibel, J.; et al. The Effect of Exercise on Body Composition and Bone Mineral Density in Breast Cancer Survivors taking Aromatase Inhibitors. Obesity 2017, 25, 346-351. [CrossRef]

26. Harvie, M. The importance of controlling body weight after a diagnosis of breast cancer: The role of diet and exercise in breast cancer patient management. In Exercise and Cancer Survivorship: Impact on Health Outcomes and Quality of Life; Saxton, J., Daley, A., Eds.; Springer: New York, NY, USA, 2010; pp. 73-96.

27. Iyengar, N.M.; Gucalp, A.; Dannenberg, A.J.; Hudis, C.A. Obesity and cancer mechanisms: Tumor microenvironment and inflammation. J. Clin. Oncol. 2016, 34, 4270-4276. [CrossRef]

28. Healy, L.A.; Ryan, A.M.; Carroll, P.; Ennis, D.; Crowley, V.; Boyle, T.; Kennedy, M.J.; Connolly, E.; Reynolds, J.V. Metabolic syndrome, central obesity and insulin resistance are associated with adverse pathological features in postmenopausal breast. Clin. Oncol. 2010, 22, 281-288. [CrossRef]

29. Clarkson, P.M.; Kaufman, S.A. Should resistance exercise be recommended during breast cancer treatment? Med. Hypotheses 2010, 75, 192-195. [CrossRef]

30. Gunter, M.J.; Xie, X.; Xue, X.; Kabat, G.C.; Rohan, T.E.; Wassertheil-Smoller, S.; Ho, G.Y.F.; Wylie-Rosett, J.; Greco, T.; Yu, H.; et al. Breast cancer risk in metabolically healthy but overweight postmenopausal women. Cancer Res. 2015, 75, 270-274. [CrossRef]

31. Iyengar, N.M.; Arthur, R.; Manson, J.; Chlebowski, R.T.; Kroenke, C.H.; Peterson, L.; Cheng, T.Y.D.; Feliciano, E.C.; Lane, D.; Luo, J.; et al. Association of Body Fat and Risk of Breast Cancer in Postmenopausal Women with Normal Body Mass Index. JAMA Oncol. 2019, 5, 155-163. [CrossRef]

32. Saad, F.; Adachi, J.D.; Brown, J.P.; Canning, L.A.; Gelmon, K.A.; Josse, R.G.; Pritchard, K.I. Cancer treatment-induced bone loss in breast and prostate cancer. J. Clin. Oncol. 2008, 26, 5465-5476. [CrossRef]

33. Bardia, A.; Arieas, E.T.; Zhang, Z.; Defilippis, A.; Tarpinian, K.; Jeter, S.; Nguyen, A.; Henry, N.L.; Flockhart, D.A.; Hayes, D.F.; et al. Comparison of breast cancer recurrence risk and cardiovascular disease incidence risk among postmenopausal women with breast cancer. Breast Cancer Res. Treat. 2012, 131, 907-914. [CrossRef]

34. Morris, P.G.; Hudis, C.A.; Giri, D.; Morrow, M.; Falcone, D.J.; Zhou, X.K.; Du, B.; Brogi, E.; Crawford, C.B.; Kopelovich, L.; et al. Inflammation and increased aromatase expression occur in the breast tissue of obese women with breast cancer. Cancer Prev. Res. 2011, 4, 1021-1029. [CrossRef]

35. McTiernan, A.; Kooperberg, C.; White, E.; Wilcox, S.; Coates, R.; Adams-Campbell, L.L.; Woods, N.; Ockene, J. Recreational physical activity and the risk of breast cancer in postmenopausal women: The Women's Health Initiative Cohort Study. JAMA 2003, 290, 1331-1336. [CrossRef]

36. Chan, D.S.; Vieira, A.R.; Aune, D.; Bandera, E.V.; Greenwood, D.C.; McTiernan, A.; Rosenblatt, D.N.; Thune, I.; Vieira, R.; Norat, T. Body mass index and survival in women with breast cancer-systematic literature review and meta-analysis of 82 follow-up studies. Ann. Oncol. 2014, 25, 1901-1914. [CrossRef]

37. Coin, A.; Giannini, S.; Minicuci, N.; Rinaldi, G.; Pedrazzoni, M.; Minisola, S.; Rossini, M.; Puente, A.D.; Inelmen, E.M.; Manzato, E.; et al. Limb fat-free mass and fat mass reference values by dual-energy X-ray absorptiometry (DEXA) in a 20-80 year-old Italian population. Clin. Nutr. 2012, 31, 506-511. [CrossRef]

38. Gomes, P.R.L.; Freitas Junior, I.F.; Silva, C.B.; Gomes, I.C.; Rocha, A.P.R.; Salgado, A.S.I.; do Carmo, E.M. Short-term changes in handgrip strength, body composition, and lymphedema induced by breast cancer surgery. Rev. Bras. Ginecol. Obstet. 2014, 36, 244-250. [CrossRef]

39. Vance, V.; Mourtzakis, M.; McCargar, L.; Hanning, R. Weight gain in breast cancer survivors: Prevalence, pattern and health consequences. Obes. Rev. 2011, 12, 282-294. [CrossRef]

40. Van den Berg, M.M.G.A.; Winkels, R.M.; de Kruif, J.T.; van Laarhoven, H.W.M.; Visser, M.; de Vries, J.H.M.; de Vries, Y.C.; Kampman, E. Weight change during chemotherapy in breast cancer patients: A meta-analysis. BMC Cancer 2017, 17, 259. [CrossRef]

41. Prokopowicz, K.; Kozdroń, E.; Prokopowicz, G.; Molik, B.; Berk, A.; Mucha, J. Conditions of physical activity undertaken by women after surgical breast cancer treatment. Hygeia Public Health 2018, 53, 100-105.

42. Ridan, T.; Zdebska, S.; Ogrodzka, K.; Opuchlik, A. Evaluation of physical activity level in women after single breast mastectomy. Probl. Hyg. Epidemiol. 2015, 96, 181-186.

43. Hashemi Bani, S.H.; Karimi, S.; Mahboobi, H. Lifestyle changes for prevention of breast cancer. Electron. Physician 2014, 3, 894-905. 
44. Irwin, M.L.; McTiernan, A.; Manson, J.E.; Thomson, C.A.; Sternfeld, B.; Stefanick, M.L.; Wactawski-Wende, J.; Craft, L.; Lane, D.; Martin, L.W.; et al. Physical activity and survival in postmenopausal women with breast cancer: Results from the women's health initiative. Cancer Prev. Res. 2011, 4, 522-529. [CrossRef] [PubMed]

45. Deluche, E.; Leobon, S.; Desport, J.C.; Venat-Bouvet, L.; Usseglio, J.; Tubiana-Mathieu, N. Impact of body composition on outcome in patients with early breast cancer. Support. Care Cancer 2018, 26, 861-868. [CrossRef]

46. Brorson, H.; Ohlin, K.; Olsson, G.; Karlsson, M.K. Breast cancer-related chronic arm lymphedema is associated with excess adipose and muscle tissue. Lymphat Res. Biol. 2009, 7, 3-10. [CrossRef] [PubMed]

Publisher's Note: MDPI stays neutral with regard to jurisdictional claims in published maps and institutional affiliations.

(C) 2020 by the authors. Licensee MDPI, Basel, Switzerland. This article is an open access article distributed under the terms and conditions of the Creative Commons Attribution (CC BY) license (http://creativecommons.org/licenses/by/4.0/). 